\title{
Autoimmune Neurogenic Dysphagia
}

\author{
Panos Stathopoulos ${ }^{1} \cdot$ Marinos C. Dalakas ${ }^{2,3}$ (D)
}

Received: 18 January 2021 / Accepted: 23 June 2021 / Published online: 5 July 2021

(c) The Author(s) 2021

\begin{abstract}
Autoimmune neurogenic dysphagia refers to manifestation of dysphagia due to autoimmune diseases affecting muscle, neuromuscular junction, nerves, roots, brainstem, or cortex. Dysphagia is either part of the evolving clinical symptomatology of an underlying neurological autoimmunity or occurs as a sole manifestation, acutely or insidiously. This opinion article reviews the autoimmune neurological causes of dysphagia, highlights clinical clues and laboratory testing that facilitate early diagnosis, especially when dysphagia is the presenting symptom, and outlines the most effective immunotherapeutic approaches. Dysphagia is common in inflammatory myopathies, most prominently in inclusion body myositis, and is frequent in myasthenia gravis, occurring early in bulbar-onset disease or during the course of progressive, generalized disease. Acute-onset dysphagia is often seen in Guillain-Barre syndrome variants and slowly progressive dysphagia in paraneoplastic neuropathies highlighted by the presence of specific autoantibodies. The most common causes of CNS autoimmune dysphagia are demyelinating and inflammatory lesions in the brainstem, occurring in patients with multiple sclerosis and neuromyelitis optica spectrum disorders. Less common, but often overlooked, is dysphagia in stiff-person syndrome especially in conjunction with cerebellar ataxia and high anti-GAD autoantibodies, and in gastrointestinal dysmotility syndromes associated with autoantibodies against the ganglionic acetyl-choline receptor. In the setting of many neurological autoimmunities, acute-onset or progressive dysphagia is a potentially treatable condition, requiring increased awareness for prompt diagnosis and early immunotherapy initiation.
\end{abstract}

Keywords Dysphagia $\cdot$ Deglutition $\cdot$ Deglutition disorders $\cdot$ Neurological autoimmunity $\cdot$ Inflammatory myopathies . Myasthenia gravis · Autoimmune neuropathies · Neuromyelitis · Stiff-person syndrome $\cdot$ Immunotherapies

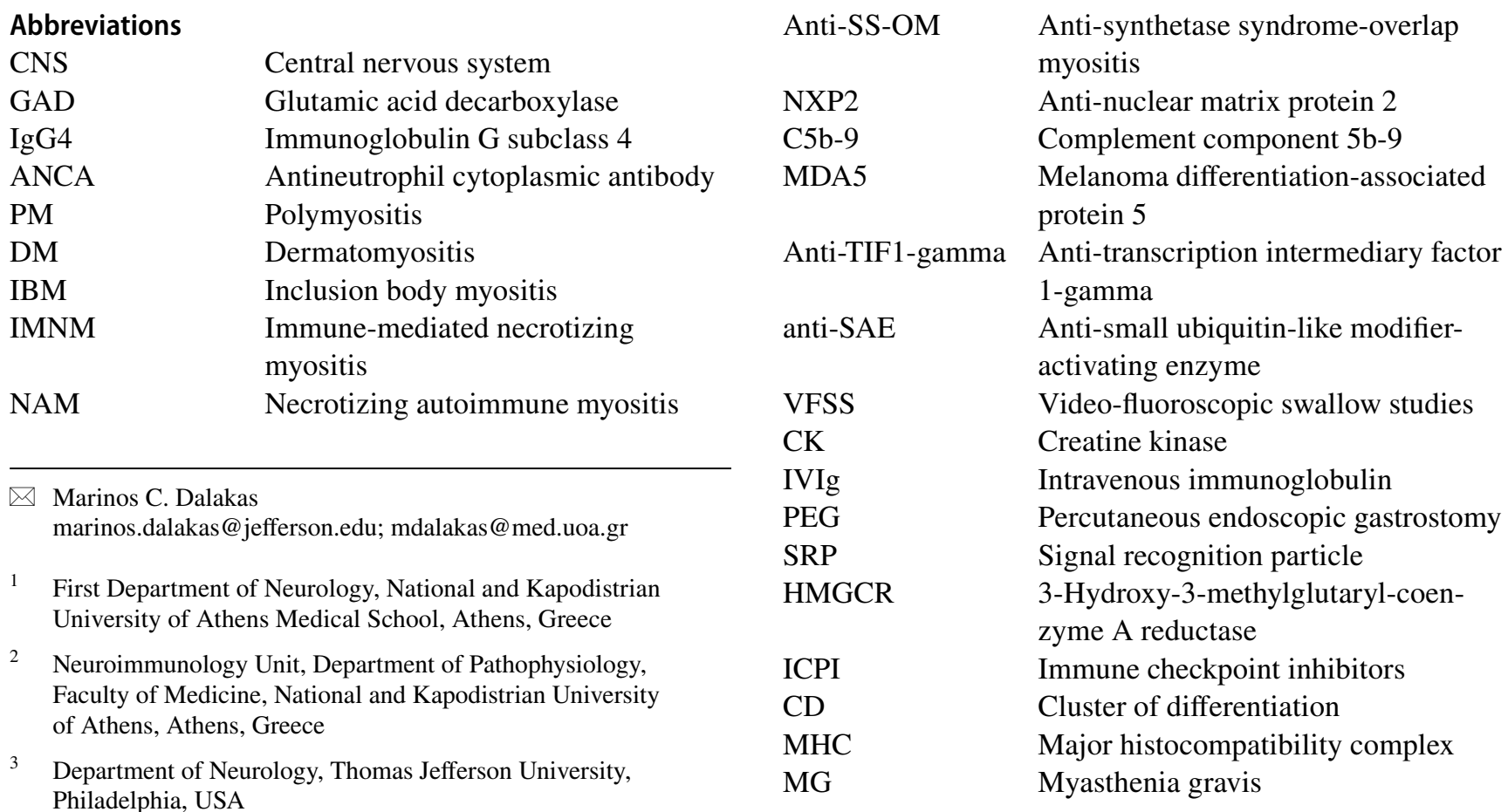




$\begin{array}{ll}\text { AChR } & \text { Acetyl-choline receptors } \\ \text { MuSK } & \text { Muscle-specific kinase } \\ \text { LEMS } & \text { Lambert-eaton myasthenic syndrome } \\ \text { VGCC } & \text { Voltage-gated calcium channels } \\ \text { ALS } & \text { Amyotrophic lateral sclerosis } \\ \text { FcRn } & \text { Neonatal Fc receptor } \\ \text { GBS } & \text { Guillain-Barre syndrome } \\ \text { MFS } & \text { Miller Fisher syndrome } \\ \text { PCB } & \text { Pharyngeal-cervical-brachial variant } \\ \text { SARS-CoV-2 } & \text { Severe adult respiratory syndrome } \\ & \text { coronavirus 2 } \\ \text { EMG } & \text { Electromyogram } \\ \text { PLEX } & \text { Plasma exchange } \\ \text { CT } & \text { Computer tomography } \\ \text { MRI } & \text { Magnetic resonance imaging } \\ \text { PET } & \text { Positron emission tomography } \\ \text { TNF } & \text { Tumor necrosis factor } \\ \text { SS } & \text { Sjogren's syndrome } \\ \text { MS } & \text { Multiple sclerosis } \\ \text { NMO-SD } & \text { Neuromyelitis optica spectrum } \\ & \text { disorders } \\ \text { EDSS } & \text { Expanded disability status scale } \\ \text { FESS } & \text { Fiber endoscopic swallow studies } \\ \text { CSF } & \text { Cerebrospinal fluid } \\ \text { AQP4 } & \text { Aquaporin 4 } \\ \text { MOG } & \text { Myelin oligodendrocyte glycoprotein } \\ \text { SPS } & \text { Stiff-Person syndrome } \\ \text { PERM } & \text { Progressive encephalopathy with } \\ \text { GABAR } & \text { rigidity and myoclonus } \\ \text { NMDAR } & \text { Gamma aminobutyric acid receptor } \\ \text { ADEM } & \text { N-methyl-D-aspartate receptor } \\ & \text { Acute disseminated } \\ \text { CLIPPERS } & \text { encephalomyelitis } \\ & \text { Chronic lymphocytic inflammation } \\ \text { DPPX } & \text { with pontine perivascular enhance- } \\ \text { GFAP } & \text { ment responsive to steroids } \\ & \text { Dipeptidyl peptidase-like protein-6 } \\ & \end{array}$

\section{Introduction}

Dysphagia, manifested as difficulty swallowing solids or liquids, is a symptom of variable severity, from mild to severe, which affects quality of life and may lead to lifethreatening complications including malnutrition, weight loss, and aspiration pneumonia. Swallowing is a complex mechanism, requiring the coordination of both skeletal and smooth muscles and the involvement of the central, peripheral, and autonomic nervous system that works in synchrony to coordinate the different phases (oral, pharyngeal, and esophageal). Although dysphagia is commonly caused by a local oropharyngeal or a generalized, systemic medical condition, it can be entirely due to a neurological disease such as stroke, head injury, dementia, and Parkinson's disease, cerebral palsy, or motor neuron disease (Amyotrophic Lateral Sclerosis). In addition, dysphagia can be the first or sole manifestation of an autoimmune neurological disease, or occurs within the complex of symptoms in the course of many neurological autoimmunities. Since treatment of dysphagia depends on the causative process, identifying an autoimmune trigger or association is critical, because patients with autoimmune dysphagia can respond to immunotherapies. Autoimmune neurogenic dysphagia is, therefore, an important and rather underestimated category that deserves special attention by all specialties.

Autoimmune causes of dysphagia can be gastroenterological, such as IgG4-related disease and eosinophilic esophagitis; dermatological, such as pemphigus vulgaris and bullous pemphigoid; rheumatologic, such as scleroderma, Sjogren's syndrome, systemic lupus erythematosus, rheumatoid arthritis, Behcet disease, ANCA-associated vasculitis, or granulomatosis with polyangiitis; and neurologic. In this opinion article, we review the autoimmune neurological causes of dysphagia, highlight clinical clues and laboratory tests that facilitate early diagnosis, especially when dysphagia is the presenting symptom, and outline the most effective immunotherapeutic approaches. We focus on common autoimmune neurological diseases, such as inflammatory autoimmune myopathies, myasthenia gravis, autoimmune cranial neuropathies in the spectrum of Guillain-Barre syndrome and multiple sclerosis, and less common like neuromyelitis optica, Stiff-person spectrum disorders and ganglionic acetyl-choline receptor autoantibody-related autoimmunities.

\section{Autoimmune Neurological Disorders with Dysphagia}

Autoimmune neurogenic dysphagia can be seen with diseases affecting muscle, neuromuscular junction, cranial nerves, brainstem, or corticospinal CNS tracts as the first manifestation of an autoimmune process or during the course of a progressive neurological autoimmune disease. The most common disorders in this category, listed in Table 1 with anatomic sequence, include inflammatory myopathies; neuromuscular junction disorders; autoimmune cranial neuropathies; autoimmune ganglionopathies or dysautonomic disorders; and autoimmune central nervous system diseases.

\section{Inflammatory Myopathies}

The inflammatory myopathies constitute a heterogeneous group of muscle diseases originally classified to include polymyositis (PM), dermatomyositis (DM), and inclusion 
Table 1 Autoimmune neurological disorders with dysphagia

\begin{tabular}{l} 
A. Inflammatory myopathies \\
1. Dermatomyositis (DM) \\
2. Polymyositis (PM) \\
3. Anti-synthetase syndrome-Overlap Myositis (Anti-SS-OM) \\
4. Immune-mediated necrotizing myopathy (IMNM or NAM) \\
5. Inclusion Body Myositis (IBM) \\
B. Neuromuscular junction disorders \\
1. Myasthenia gravis (MG) \\
2. Lambert-Eaton myasthenic syndrome (LEMS) \\
C. Autoimmune cranial neuropathies \\
1. Guillain Barre syndrome (GBS) and variants \\
2. Autoimmune paraneoplastic neuropathies \\
3. Neuropathies in systemic autoimmune illnesses \\
D. Autoimmune ganglionopathies and autonomic nervous system \\
disorders \\
E. Autoimmune centran nervous system disorders \\
1. Multiple sclerosis (MS) \\
2. Neuromyelitis optica spectrum disorders (NMO-SD) \\
3. Glutamic acid decarboxylase (GAD) autoantibody-associated \\
disorders \\
4. Other autoimmune encephalitides \\
\hline
\end{tabular}

body myositis (IBM) [1, 2] but now evolved to also include immune-mediated necrotizing myositis (IMNM) or necrotizing autoimmune myositis (NAM), and the anti-synthetase syndrome-overlap Myositis (Anti-SS-OM) [3, 4]. Dysphagia occurs in all subtypes but in our experience, it is especially prominent in IBM, followed by Anti-SS-OM, DM, and NAM.

Despite the heterogeneity among the group of inflammatory myopathies, several studies have assessed prevalence of dysphagia in pooled cohorts of different disease subsets. A meta-analysis, including 116 studies and 10,382 subjects, found that $36 \%$ of patients with inflammatory myopathy had dysphagia [5]. Of note, when only studies with low chances of bias were included, the prevalence of dysphagia rose to $82 \%$ underscoring the need for high degree of suspicion in early identification. Risk factors for dysphagia were the diagnosis of IBM, an underlying malignancy, or a suspected malignancy as in DM patients with anti-nuclear matrix protein 2 (NXP2) antibodies [5]. A retrospective chartreview study found that $23 \%$ among $230 \mathrm{DM} / \mathrm{PM}$ patients had dysphagia at disease presentation, but as the disease progressed $58 \%$ of the patients developed dysphagia [6]. A second, smaller, retrospective, questionnaire-based study of 50 patients (35 with DM and 8 with PM), found dysphagia at diagnosis in $10 \%$ of the patients [7]. Better insight about the prevalence of dysphagia at disease onset or throughout the course of the disease is provided by studies that focus on specific inflammatory myopathy subsets as discussed below. In our overall experience with many inflammatory myopathy patients, dysphagia occurs during the course of the disease and not at presentation, with the exception of IBM where it can be an early symptom generating diagnostic challenges.

\section{Dermatomyositis}

Dermatomyositis (DM) occurs in children and adults and presents with characteristic skin manifestations accompanying or preceding muscle weakness. Periorbital heliotrope (blue-purple) rash with edema, erythematous rash on face, knees, elbows, malleoli, neck, anterior chest (in V-sign), back and shoulders (in shawl sign), and knuckles with a violaceous eruption (Gottron's rash) that evolves into a scaling discoloration, are typical skin lesions. Muscle histology shows inflammation predominantly perivascularly, in the interfascicular septae or at the periphery of the fascicle with characteristic perifascicular atrophy and abnormalities of the capillaries [2]. In DM, there is early activation of complement with the C5b-9 membranolytic-attack complex deposited on the endothelial cells leading to capillary necrosis, reduction of endomysial capillaries, ischemia, and muscle fiber destruction resembling microinfarcts [1-3]. In addition, autoantibodies against melanoma differentiation-associated protein 5 (MDA5), anti-transcription intermediary factor 1-gamma (anti-TIF1-gamma), anti-NXP2, and anti-small ubiquitin-like modifier-activating enzyme (anti-SAE) can be present. Among these antibodies, anti-NXP2 that often denotes an underlying malignancy, may correlate with dysphagia [8]. About 15\% of DM patients may overall have an underlying malignancy. Dermatomyositis may also co-exist with other systemic autoimmunities, most often systemic sclerosis which by itself is associated with dysphagia due to esophageal fibrosis [9].

Dysphagia in DM ranges from $31 \%(N=3274)$ in a rather heterogeneous meta-analysis, to $43 \%(N=949)$ in the Euromyositis registry, and even over $60 \%(N=117)$ in a cohesive retrospective cohort $[5,6,10]$. In a more targeted retrospective investigation of patients with inflammatory myopathies and dysphagia that also included video-fluoroscopic swallow studies (VFSS), dysphagia was rarely the presenting symptom of DM [11, 12], an observation consistent with our own experience in large series. In one of those studies, dysphagia was associated with increased mortality, with 5 of 18 dysphagic patients dying within the first year of follow-up; this study is not, however, representative because a number of these patients had malignancy and no details on early diagnosis or immunotherapy initiation were provided [11].

Disease suspicion should be raised by the presence of the characteristic skin lesions often associated with increased levels of creatine kinase (CK). The diagnosis is confirmed with muscle biopsy. Treatment with high-dose steroids and steroid-sparing agents (especially methotrexate, azathioprine, or mycophenolate) is helpful early in the disease. In 
poorly responding patients, high-dose intravenous immunoglobulin (IVIg) is the treatment of choice [13]. In the only controlled study, IVIg had a dramatic effect on patients' proximal muscle strength and neuromuscular activities, based on a 20-item neuromuscular symptom score that included dysphagia [13]. Because DM is a complementmediated microangiopathy, the clinical efficacy of IVIg is immunopathologically supported by inhibition of complement activation and interception of membranolytic-attack complex on endothelial cells, restoring the integrity and population of endomysial capillaries [14]. If IVIg is not sufficiently effective, rituximab is initiated. Rehabilitation measures and compensatory interventions (special diet, feeding techniques, such as small bites and alternating solids and liquids, and exercises such as tongue base retraction and effortful swallow) may provide additional benefits [11]. In severe early cases, percutaneous endoscopic gastrostomy (PEG) may be initially required to prevent aspiration pneumonia and malnutrition until the aforementioned immunotherapies take effect, typically within $2-3$ months. A common mistake we have encountered is the prolonged use of PEG that leads to severe atrophy of the pharyngeal and laryngeal muscles and more difficulty returning to normalcy.

\section{Polymyositis}

Polymyositis (PM) is a very rare entity. In our experience, most patients referred for PM have another muscle disease, most often IBM, NAM, or an inflammatory dystrophy. Based on the aforementioned older studies, dysphagia occurs in $35 \%-50 \%$ of PM patients $[5,6,10]$, but these data should be interpreted with caution because it is highly unlikely that these estimates refer to PM; they do, however, reflect that dysphagia is a frequent symptom in inflammatory myopathies.

\section{Anti-Synthetase Syndrome-Overlap Myositis}

Anti-synthetase syndrome-overlap Myositis (Anti-SS-OM) is now a distinct entity that often presents with systemic sclerosis-like lesions, mild-to-moderate proximal muscle weakness, arthritis in the form of subluxation of the interphalangeal joints, "mechanic's hands," Raynaud phenomenon, and interstitial lung disease [3]. The syndrome is highlighted by the presence of various anti-aminoacyl transfer RNA synthetase autoantibodies, primarily antiJo-1; hence, its name "anti-Jo-1 syndrome." These patients' muscle biopsy has distinct findings with necrotizing features in the perimysium and perifascicular muscle fibers [3, 4]. Dysphagia is common (reported in $26 \%$ of anti-SS-OM in the Euromyositis registry [10]), but it is clinically mild to moderate and not as severe as in the other inflammatory myopathy subtypes. In a retrospective study of patients with inflammatory myopathies and dysphagia that included VFSS in approximately half the patients, dysphagia was the leading presenting symptom in one of 9 anti-SS-OM patients [11]. Immunotherapy for dysphagia in anti-SS-OM is the same as in DM. In our experience, dysphagia anti-SS-OM patients respond to therapies much better and faster than in DM; this is also corroborated by the 5-year survival data when immunotherapy was applied to nine anti-SS-OM patients with dysphagia as their leading symptom [11].

\section{Immune-Mediated Necrotizing Myopathy}

Immune-mediated necrotizing myopathy (IMNM) or necrotizing autoimmune myositis (NAM) has now evolved into the most common inflammatory myopathy in all age groups [3]. It starts either acutely, reaching its peak over days or weeks, or subacutely, progressing steadily and causing severe muscle weakness, including dysphagia, and very high (in the thousands) CK levels [3]. NAM may also occur after viral infections and in association with cancer or immune checkpoint inhibitors. Although often attributed to statins or over-diagnosed as a "statin-myopathy" in patients on chronic statin treatment, there is no convincing evidence that statins play a triggering role in patients who develop subacute NAM while taking statins for years [1,14-16]. Since NAM is now the commonest inflammatory myopathy and more than $25 \%$ of Americans above 40 years take statins, the association between statins and NAM is likely a chance phenomenon $[15,16]$. Most NAM patients have antibodies against signal recognition particle (SRP) or 3-hydroxy-3-methylglutarylcoenzyme A reductase (HMGCR), a ubiquitous and nonmuscle-specific antigen within the endoplasmic reticulum, more often seen in NAM patients associated with cancer.

Dysphagia was observed in more than $30 \%$ of NAM patients in the Euromyositis registry (total $N=3067$, NAM $N=107$ ) [11]. In an in-depth investigation (including VFSS) of five NAM patients with early or prominent dysphagia triggered by immune checkpoint inhibitors (ICPI), only one of four examined patients had cricopharyngeal prominence on VFSS, but all had impaired pharyngeal contraction and three impaired tongue base retraction and epiglottic inversion/laryngeal elevation with aspiration; concurrent ophthalmoparesis was also noted, as commonly observed in ICPItriggered NAM [12]. In our experience, most NAM patients, even those with severe disease, respond to immunotherapy with intravenously administered corticosteroids in the acute phase, followed by IVIg and, if needed, rituximab.

\section{Inclusion Body Myositis}

Inclusion Body Myositis (IBM) is the most common and disabling inflammatory myopathy above the age of 50 [1-3] and the most common cause of disabling dysphagia 
related to inflammatory myopathies. It starts insidiously, over years, at times asymmetrically and progresses steadily simulating a late-life muscular dystrophy or slowly progressive motor neuron disease leading to significant disability [1-3]. Although IBM is commonly suspected when a patient with presumed PM does not respond to therapy [1-3], early involvement of distal muscles, especially foot extensors and finger flexors, atrophy of the forearms and quadriceps muscles, dysphagia, frequent falls due to quadriceps muscle weakness causing buckling of the knees and mild facial muscle weakness are clues to early clinical diagnosis [1-3]. The diagnosis based on the distinct clinical phenotype is confirmed with the muscle biopsy that shows inflammatory infiltrates consisting predominantly of $\mathrm{CD} 8^{+}$cytotoxic T-cells invading muscle fibers expressing MHC-I antigen, and autophagic vacuoles with congophilic amyloid deposits [1-3]. Antibodies against cytosolic 5'-nucleotidase 1A $(\mathrm{cN} 1 \mathrm{~A})$ are detected in $50 \%$ of patients but lack specificity.

Dysphagia is a disabling clinical manifestation of IBM and more frequent than in any other inflammatory myopathy [17-24]. Cumulative dysphagia prevalence was up to $50 \%$ in the Euromyositis registry and 56\% in a meta-analysis $[5,10]$, but these studies were quite heterogeneous and not clinically detailed. In several single-center studies with reliable data, dysphagia was the sole presenting symptom or one of the main presenting symptoms in $10 \%$ of IBM patients $[12,22,23]$, with the frequency rising up to $40 \%$ by the time of diagnosis [19]. Targeted in-person questioning of IBM patients revealed dysphagia in $65 \%(N=57)$ or up to $80 \%$ $(n=19)$; VFSS revealed signs of impaired propulsion in $77 \%$ (repetitive swallowing 25\%, residues 36\%, and cricopharyngeal dysfunction 16\%) and aspiration-related signs (mostly inadequate epiglottal downward tilting) in 53\% $(N=43)$ $[19,20]$. In a study of myopathies with early or prominent dysphagia, 15 patients with IBM were studied with VFSS [12]; an impaired pharyngeal contraction was noted in 9, impaired tongue base retraction in 10 , and epiglottic inversion/laryngeal elevation in 8 with their pharyngeal phase more severely affected than the oral phase; aspiration during the study was observed in 3 patients [12]. In a series of 35 IBM patients studied with VFSS, pharyngeal pooling was observed in $85 \%$, impaired tongue base retraction in $76 \%$, and impaired laryngeal elevation in $50 \%$; in $26 \%$, aspiration was noted during the study [11]. A questionnaire in 64 IBM patients followed over a median period of 12 years, found that dysphagia was present in $80 \%$ of the 15 survivors [17]. The presence of cricopharyngeal sphincter dysfunction/ bar (possibly amenable to intervention) ranged from $42 \%$ on barium swallow [19] to $37-47 \%$ by VFSS $[11,17,18]$. Not surprisingly, studies focused on dysphagia showed that among all inflammatory myopathies, most patients had IBM $[11,12]$. Of importance, isolated dysphagia can be the presenting symptom of IBM [23] or one of the presenting symptoms in $42 \%$ of patients [11]. In our experience, progressive dysphagia in IBM is a sign of more aggressive disease, as recently confirmed by others [12].

The only proven treatment that may partially help the dysphagia in some patients with IBM is IVIg based on a controlled study we have conducted [21]. In this study, IVIg did not show significant benefit in muscle strength but did show significant improvement in swallowing, as assessed with VFSS combined with a sensitive quantitative ultrasound method that objectively measures the mean time (in seconds) needed to complete three dry and three wet swallows (Fig. 1 and Table 2) [21]. All immunosuppressive agents used in IBM have failed probably because the disease starts long before patients seek medical advice. Glucocorticoids, methotrexate, cyclosporine, azathioprine, or mycophenolate is
Fig. 1 A patient with Inclusion Body Myositis (IBM) participating in an NIH-controlled clinical trial with high-dose intravenous immunoglobulin (IVIG). Left: Before therapy, a patient with swallowing difficulty due to IBM is using a partially cut cup designed by the Swallowing Section at the NIH to raise the cup when drinking without the need to extend the head backwards due to a choking feeling. Right: After IVIg therapy, swallowing improved and patient was able to drink from a normal cup (Dalakas et al. [21])
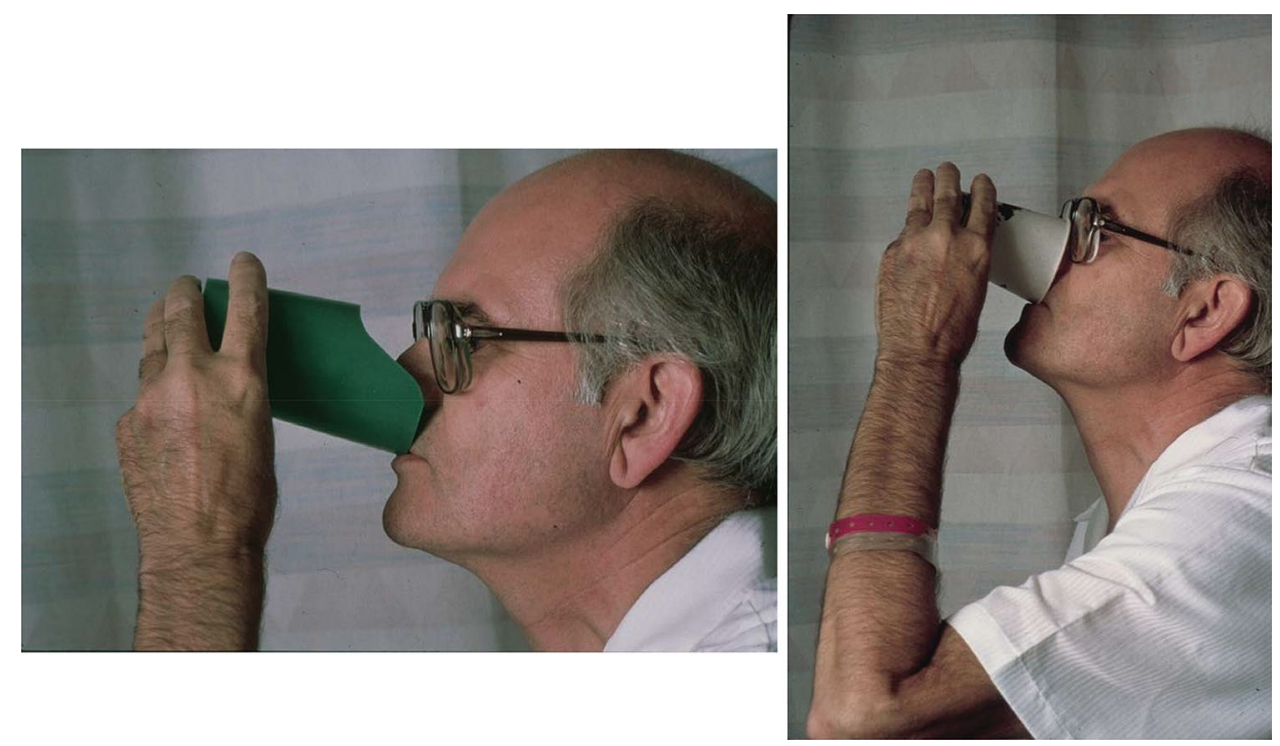
Table 2 Mean duration (seconds) of ultrasound-recorded swallows at baseline, 3 months, and end of crossover in IBM patients treated with placebo or IVIg

\begin{tabular}{|c|c|c|c|c|}
\hline & Type of swallow & Baseline & $\begin{array}{l}\text { Three months } \\
\text { Placebo }\end{array}$ & $\begin{array}{l}\text { Crossover } \\
\text { IVIg }\end{array}$ \\
\hline \multirow{7}{*}{$\begin{array}{l}\text { Patients receiving randomly assigned placebo first } \\
(n=10)\end{array}$} & D1 & 2.33 & 1.83 & 1.91 \\
\hline & D2 & 2.15 & 1.75 & 1.88 \\
\hline & D3 & $1.84^{*}$ & $2.84^{*}$ & $1.83^{*}$ \\
\hline & W1 & $1.59^{*}$ & $2.25^{*}$ & $1.86^{*}$ \\
\hline & W2 & 2.49 & 1.96 & 2.00 \\
\hline & W3 & $1.59^{*}$ & $2.07^{*}$ & $2.44^{*}$ \\
\hline & & & IVIg & Placebo \\
\hline \multirow{6}{*}{$\begin{array}{l}\text { Patients receiving randomly assigned IVIg first } \\
(n=9)\end{array}$} & D1 & $3.00^{*}$ & $1.62^{*}$ & 1.47 \\
\hline & D2 & $3.37^{*}$ & $2.02^{*}$ & 2.31 \\
\hline & D3 & 2.35 & $2.74^{*}$ & $1.85^{*}$ \\
\hline & W1 & 1.82 & 1.86 & 1.47 \\
\hline & W2 & $1.73^{*}$ & $1.24^{*}$ & 1.54 \\
\hline & W3 & $1.98^{*}$ & $1.49^{*}$ & 1.48 \\
\hline
\end{tabular}

Reproduced from Dalakas et al. [21]

D1-3 three dry swallows, W1-3 three wet swallows, IBM inclusion body myositis, IVIg intravenous immunoglobulin

* $p=0.05$

ineffective, and although some patients initially experience mild improvements, there is no long-term benefit. Treatment with alemtuzumab, a B and T cell-depleting anti-CD52 monoclonal antibody, has shown some promising results in an uncontrolled trial [25], while treatment with canakinumab, an anti-IL-1 $\beta$ monoclonal antibody, yielded mixed results in a small trial of 5 patients [26]. Anakinra, an IL-1 receptor blocker, had also shown mild short-term improvements in a subset of patients in the first series [27] and in a later study of 15 patients [28]. Because of the common presence of a cricopharyngeal bar, invasive procedures including balloon dilatation and myotomy can lead to improvement of symptoms in patients with serious dysphagia and weight loss prior to PEG insertion [20, 29-33], although this effect was not long lasting after 5 years [17]. In our experience, Botox injections have not been helpful. Regarding rehabilitation techniques, the Mendelsohn maneuver (conscious prolongation of peak-swallow laryngeal elevation) has shown some efficacious results [30]. Overall, although life expectancy has been reported unaffected, most IBM patients with endstage disease require assistive devices such as cane, walker, or wheelchair [34]; in those patients, dysphagia is the most life-threatening symptom if not responding to IVIg.

\section{Neuromuscular Junction Disorders}

Myasthenia gravis (MG) is a prototypic autoimmune disease manifesting with skeletal, bulbar, and respiratory muscle weakness, fatigue especially with repetitive movement or muscle actions, and impaired chewing or swallowing [35]. The MG symptoms and pathology are mediated by autoantibodies against nicotinic acetyl-choline receptors (AChR), detected in $85 \%$ of patients. The AChR antibodies fix complement at the end-plate region, leading to destruction of the AChRs and simplification of the endplates. In $15 \%$ of patients, anti-AChR antibodies are not detected; of those, $50 \%$, comprising 5-8\% of all AChR-negative MG cases, are positive for antibodies against muscle-specific kinase (MuSK), a transmembrane polypeptide expressed at the neuromuscular junction that plays a fundamental role in AChR clustering [36]. Anti-MuSK antibodies are of the IgG4 subclass and are typically non-complement binding. MG may have an early or late onset and can remain ocular, when symptoms are limited to extraocular muscles (ptosis, diplopia), or become generalized, when weakness affects most muscle groups. MuSK-MG commonly presents with bulbar symptoms such as dysphagia, dysphonia, dysarthria, and difficulty chewing [37], with dysphagia being more common than in the AChR-MG [38].

Dysphagia in MG (as in all cases of neurogenic dysphagia) manifests with difficulty swallowing both solids and liquids and is primarily caused by pharyngeal and laryngeal muscle weakness and fatigue, and secondarily esophageal hypomotility [39, 40]; the latter is confirmed by esophageal manometry that reveals decreased amplitude of upper esophageal sphincter contractions and esophageal peristaltic waves [41]. Weakness and fatigue can also affect mastication muscles, causing difficulty in 
chewing. In MG, dysphagia is usually accompanied by other bulbar symptoms such as dysphonia and dysarthria, ocular manifestations like ptosis, and diplopia, and axial or neck muscle weakness $[37,42]$. In a large prospective study, clinically assessed dysphagia was present at disease onset in $25 \%$ of $84 \mathrm{MG}$ patients [43]. In a study that examined $175 \mathrm{MG}$ patients primarily presenting with head and neck symptoms, clinically assessed dysphagia was the primary symptom in $15 \%$ and the secondary in $12 \%$ [44]. Dysphagia can also be part of the clinical syndrome in another autoimmune neuromuscular junction disorder, the Lambert-Eaton Myasthenic Syndrome (LEMS), which can be paraneoplastic in about $50-75 \%$ of the patients, and is associated with antibodies against the P/Q type voltagegated calcium channels (VGCC) at the presynaptic nerve terminals [45].

The diagnosis of MG is solidified by testing the presence of serum AChR or MuSK autoantibodies. In the 7\% of seronegative MG, the diagnosis, if clinically suspected based on fatiguing weakness, is confirmed with single-fiber EMG or repetitive nerve stimulation studies. Dysphagia related to seronegative MG should be distinguished, when advanced, from ALS, where there is also associated tongue atrophy. Electromyographic testing clarifies the diagnosis but if in doubt, a trial with oral pyridostigmine $60 \mathrm{mg}$ QID can be helpful. Identifying MG-related dysphagia is clinically rewarding for the clinicians and the patients because today MG is a treatable disease [46-48]. After excluding thymoma-seen in $10 \%$ of all AChR-MG patients-, the AChR-positive MG patients respond to pyridostigmine (an acetyl-cholinesterase inhibitor) followed by steroids and a steroid-sparing immunosuppressant such as azathioprine or most preferably today mycophenolate. Difficult cases, or when in a crisis and the dysphagia is associated with breathing difficulties, respond to IVIg and plasmapheresis [49]. Rituximab, an anti-CD20+ monoclonal antibody leading to B-cell depletion from the circulation [46, 47], is also effective in the chronic management of refractory cases. In MuSK-MG, where the antibodies are of the IgG4 subclass, rituximab is a preferred drug even early in the disease course, leading to impressive long-term remission. It is imperative, therefore, to identify early, at symptom onset, if dysphagia is due to a specific MG subtype because it is a treatable condition with the suitable agents in the majority of patients. Therapy in MG today is a success story because in addition to the aforementioned agents, new drugs, such as eculizumab, a monoclonal antibody against complement C5, are now approved for severe or refractory MG. Another new agent directed against the neonatal $\mathrm{Fc}$ receptor $(\mathrm{FcRn})$, which enhances the catabolism of circulating $\operatorname{IgG}$ antibodies, was effective in phase III trials and is in the process of gaining approval [46].

\section{Autoimmune Cranial Neuropathies}

Cranial neuropathies of autoimmune origin can also cause dysphagia, either in isolation or together with other symptoms associated with the same or neighboring nerves. Horizontal binocular diplopia (cranial nerve VI), facial paralysis, and dysarthria (cranial nerve VII), impaired hearing, balance, vertigo and tinnitus (cranial nerve VIII), impaired taste and sensation in the posterior tongue and palate (cranial nerve IX), nasal voice/hoarseness (cranial nerve X), paresis of the trapezius and sternocleidomastoid (cranial nerve XI), and dysarthria (cranial nerve XII) are among the accompanying symptoms. In the case of cranial neuropathies, the pathomechanism of dysphagia involves abnormal signal conduction to the swallowing muscles primarily affecting the pharyngeal and laryngeal muscle groups (innervated by cranial nerves IX-X), thus, causing dysphagia of both liquids and solids. Additionally, cranial nerve XII that innervates the tongue muscles, cranial nerve VII that innervates the lip muscles, and cranial nerve $\mathrm{V}$ that innervates the muscles of mastication, contribute to the oral phase of swallowing. Importantly, cranial nerve $\mathrm{X}$ carries autonomic fibers to the gastrointestinal system and influences esophageal motility. The most common autoimmune/inflammatory neurological diseases that affect cranial nerves resulting in dysphagia are as follows:

\section{Guillain-Barre Syndrome (GBS) and Its Variants}

Guillain-Barre syndrome (GBS) constitutes a monophasic, often postinfectious, autoimmune polyradiculoneuropathy that manifests acutely or subacutely (in less than 4 weeks). Typically GBS presents with ascending weakness, but in the Miller Fisher syndrome (MFS) and the pharyngeal-cervical-brachial (PCB) variant, cranial and cervical nerves are predominantly affected. The MFS variant typically presents with the triad of ataxia, ophthalmoplegia, and areflexia, while the PCB variant with cervicobrachial and oropharyngeal weakness including dysphagia [50-52]. The GBS, PCB, and MFS, as well as Bickerstaff's encephalitis, are viewed as a continuum of the same syndrome [51-53] with dysphagia even being the presenting symptom in isolated cases [54]. Notably, MFS is associated with anti-GQ1b and PCB with anti-GT1a antiganglioside autoantibodies with significant cross-reactivity [51, 52, 55]. In eight patients with anti-GT1a antibodies, clinical dysphagia was noted in $88 \%$ of cases [56]. In GBS, prevalence of clinical dysphagia ranges from $41 \%(N=54,[56])$ to $53.5 \%(N=71,[57])$, being higher $(75 \%, N=16)$ in patients admitted to ICU [58]. When dysphagia was assessed by VFSS in 14 GBS patients referred for swallowing evaluation, abnormalities were present in all the patients, with the pharyngeal swallowing phase being more severely affected than the oral phase; among these 
patients, 6 had equal involvement of oral and pharyngeal phases, 7 had more severe involvement of the pharyngeal phase, and one more severe involvement of the oral phase) [59]. Electrophysiological swallow studies also revealed silent dysphagia in $28 \%$ of non-ICU admitted GBS patients, while $38 \%$ of patients in that cohort had clinically overt dysphagia [60]. These studies collectively underline that clinicians need to remain vigilant and maintain a low threshold for nasogastric tube placement in GBS patients.

The diagnosis of GBS, MFS, and PCB is facilitated by history of preceding viral or bacterial infection, like Zika virus, SARS-CoV-2 or Campylobacter jejuni [61, 62], the presence of areflexia on examination, elevated protein in an acellular CSF, possible nerve root enhancement on MRI, and signs of neuropathy (mostly demyelinating, but sometimes axonal) on EMG. Prompt diagnosis is of importance as IVIg and PLEX are equally effective and should be initiated as soon as possible [63, 64]. In chronic inflammatory demyelinating polyradiculoneuropathy, which is the chronic counterpart of GBS and has subacute onset or a relapsing course $[65,66]$, dysphagia is uncommon but, if occurs, it responds to immunotherapy with IVIg, steroids, or rituximab in pace with the other symptoms [67-70].

\section{Autoimmune Paraneoplastic Neuropathies}

Autoimmune paraneoplastic neuropathies are caused by immunological consequences, triggered by malignant tumors targeting the nerves including those responsible for swallowing. They should be distinguished from direct infiltration of cranial nerves by a tumor, like lymphoma [71, 72], and by chemotherapy or radiation-associated neuropathies. Autoimmune neuropathies in a setting of cancers can be also triggered by immune checkpoint inhibitors that aberrantly stimulate the immune system inducing various immunological syndromes affecting nerve, muscle, neuromuscular junction, and brain $[72,73]$. Typically, but not always, the autoimmune process is demonstrated by the presence of autoantibodies [74, 75]. Paraneoplastic autoimmune neuropathies causing dysphagia, although not common, are important to recognize not only because they can precede the tumor diagnosis, but also because they can respond to immunotherapy and tumor removal $[74,76,77]$. Two antibodies in patients with small cell lung cancer, the anti-Hu (antineuronal nuclear antibody-1), [78, 79] and anti-Ri (antineuronal nuclear antibody-2) may be markers of paraneoplastic neuropathy with more prominent dysphagia [80]. In a study of 34 patients with Ri autoantibodies, clinical dysphagia was observed in seven, in conjunction with polyradiculoneuropathy, brainstem, and cerebellar involvement or encephalopathy [80]. Treatment of paraneoplastic autoimmune neuropathies consists of tumor removal and initiation of immunotherapy. The
anti-Hu syndrome, in particular, can be aggressive not well-responding immunotherapies, although some cases have responded to cyclophosphamide [76].

\section{Neuropathies in Systemic Autoimmune Diseases}

A systemic disorder where cranial neuropathies are prominent is sarcoidosis, where in $5-10 \%$ of cases, they are the presenting symptom [81]. The most common cranial neuropathy in sarcoidosis is the one affecting the facial nerve (VII), but other nerves including the IX and X can be affected, resulting in dysphagia. Of note, involvement of other organs, such as the esophagus $[82,83]$ and the swallowing muscle apparatus [84], can also cause dysphagia. Diagnosis is aided by increased circulating ACE levels, chest CT showing hilar lymphadenopathy, brain MRI showing leptomeningeal enhancement, PET-CT showing sites of active inflammation, lumbar puncture revealing high protein and oligoclonal bands, and ultimately biopsy of accessible tissue showing non-caseating granulomas. Sarcoidosis typically responds to corticosteroids and steroid-sparing agents such as mycophenolate, and in more severe cases to anti-TNF agents, such as infliximab, or anti-CD20 agents like rituximab [82-84]. Neuropathy can also occur in the course of Sjogren's syndrome (SS) [85, 86], systemic lupus erythematosus [87], and rheumatoid arthritis [88]; among these disorders, dysphagia is more prominent in SS [89], even though sometimes it is erroneously attributed to lack of saliva and esophageal hypomotility rather than involvement of the cranial nerves [90].

\section{Autoimmune Ganglionopathies and Autonomic Nervous System Disorders}

In rare instances, an autoimmune response can target the dorsal root ganglia as well as elements of the autonomic nervous system that control the gastrointestinal tract [91]. Such syndromes manifest with widespread dysautonomia including gastrointestinal dysmotility and dysphagia, and can be associated with antibodies against the ganglionic AChR (gAChR). In cases of paraneoplastic association, antibodies to $\mathrm{Hu}$ antigen or to neuronal voltage-gated calcium channel (VGCC), mainly the N-type and to a lesser degree the P/Q type (also associated with LEMS), can be seen. In the presence of $\mathrm{gAChR}$, and to a lesser degree VGCC autoantibodies, dysphagia can be directly caused by esophageal motility disorders, primarily achalasia and rarely diffuse esophageal spasm [91, 92]. Once diagnosis of an autoimmune cause is established, search for an underlying neoplasia is warranted and, accordingly, tumor removal and/ or initiation of immunotherapy. 


\section{Autoimmune CNS Disorders}

Brain regions important for swallowing localize to the anterior insula and the frontoparietal operculum, reaching via corticobulbar fibers, the brainstem nuclei of cranial nerves V, VII, XII, IX, X involved in the oral, pharyngeal, and esophageal phases of swallowing ([]. Brainstem lesions account for the majority of cases of CNS dysphagia, followed by insular and opercular lesions. Autoimmune CNS disorders causing dysphagia include multiple sclerosis (MS), Neuromyelitis Optica Spectrum Disorders (NMO-SD), hyperexcitability disorders within the spectrum of stiff-person syndrome, and autoimmune encephalitis.

\section{Multiple Sclerosis}

In Multiple sclerosis (MS), dysphagia is most often seen in primary or secondary progressive forms and correlates with the expanded disability status scale (EDSS), highlighting its association with advanced stages of the disease [93-95]. Dysphagia can be, however, seen in some acute MS cases when active demyelinating lesions affect the brainstem, and in rare cases, when active lesions affect the operculum [96]. In studies with more than 200 MS patients, where dysphagia was either evaluated clinically or by questionnaires, the prevalence of dysphagia ranged from 21 to $43 \%$ [96-103]. In studies that employed objective assessments, like VFSS and fiber endoscopic swallow studies (FESS), the dysphagia prevalence ranged from 54 to $90 \%$ [104-107] highlighting that MS clinicians should maintain a low threshold for suspecting swallowing disturbances, especially in patients with progressive MS and high EDSS scores. A VFSS study in 18 MS patients (10 with symptomatic dysphagia of varying degree and 8 asymptomatic) demonstrated aspiration in all symptomatic patients with undercoating of the epiglottis and/or laryngeal penetration; the VFSS was also abnormal in 6 of the 8 asymptomatic patients [106]. Diagnosis of MS is based on clinical, radiological, and CSF characteristics of relapses or progression and exclusion of alternative diagnoses [108, 109]. Early immunotherapy with high-efficacy treatments decreases the risk for secondary disability progression $[109,110]$. In addition to immunotherapy, rehabilitation measures such as dietary modifications, compensatory techniques, and training by a speech therapist are suggested. The value of more invasive techniques, such as Botox injection to an overactivated cricopharyngeal muscle, warrant further study [96-98, 111].

\section{Neuromyelitis Optica Spectrum Disorders}

The NMO-SD are defined, apart from optic neuritis and myelitis, by antibodies against aquaporin 4 (AQP4) [112] and myelin oligodendrocyte glycoprotein (MOG) [113].
In AQP4-NMO-SD, clinical dysphagia can be most often present in combination with other symptoms such as nausea, vomiting, intractable hiccups, dysarthria, or hypoglossal palsy $[114,115]$ but can rarely occur in isolation [116, 117]. Dysphagia is typically caused by a lesion in the brainstem and medulla oblongata and may involve the nucleus ambiguus, located close to the area postrema, which is typically affected in AQP4 NMO-SD and is responsible for the intractable hiccups, nausea, and vomiting [117, 118]. The area postrema is a circumventricular area that allows access to serum AQP4 autoantibodies, even with intact blood brain barrier [119, 120].

In a cohort of $170 \mathrm{NMO}$-SD patients (most AQP4-autoantibody positive), medulla oblongata lesions were present in $26 \%$ of patients, with $30 \%$ of them having clinical dysphagia or choking cough. In contrast, dysphagia was rare in patients without medulla oblongata lesions (noted in 1.4\%) [121, 122]. Clinical dysphagia can also occur in seronegative or MOG autoantibody-positive NMO-SD, again in connection with brainstem involvement.

Studies with FESS in 13 NMO-SD patients (6 with AQP4, 5 with MOG autoantibodies, and 2 seronegative) revealed abnormalities in 8 [124]. Interestingly, 6 of them, classified as mildly dysphagic by FESS (compared to controls), were clinically asymptomatic without MRI signs of brainstem involvement; the patients with moderately or severely dysphagia by FESS had, however, brainstem involvement. The study points out that subclinical dysphagia can be frequently present in NMO-SD, possibly indicating brainstem damage not shown by MRI, as also noted above for some MS patients [124]. Such subclinical dysphagia, identified by ultrasound, has been also seen in patients with post-polio syndrome due to late motor neuron dysfunction in the brainstem nuclei, 20-30 years after acute paralytic poliomyelitis; of interest, autoimmunity has been implicated in these patients leading to an ongoing trial with intravenous immunoglobulin [123].

Diagnosis in NMO-SD is greatly aided by testing for AQP4 and MOG autoantibodies. Optimal treatment of all symptoms, including dysphagia, involves immediate and aggressive immunotherapy with corticosteroids, plasma exchange, or IVIg, followed by maintenance therapy with mycophenolate [124], rituximab [125], inebilizumab [126], or eculizumab [127]. Similar therapies, steroids for acute relapses [128] and B-cell depletion therapies [129, 130], are also applied in MOG-positive cases.

\section{Stiff-Person Syndrome (SPS) and GAD-Spectrum Disorders (GAD-SD)}

The presence of high-titer antibodies against glutamic acid decarboxylase (GAD) in the patients' serum, also reflecting intrathecal synthesis, defines the SPS-spectrum disorders (SPS-SD or GAD-SD) that include stiff-person syndrome, 
cerebellar ataxia, autoimmune epilepsy, and encephalopathy [131-133]. SPS is clinically characterized by stiffness and muscle spasms in the trunk and proximal limbs that often include the facial muscles; $15 \%$ of patients also have ataxia, dysarthria, and dysphagia. Part of the SPS-SD is also Progressive Encephalopathy with Rigidity and Myoclonus (PERM), a distinct syndrome characterized by muscle stiffness, spasms, myoclonus, and brainstem dysfunction with oculomotor abnormalities, dysphagia, gait ataxia, prominent autonomic involvement, and the presence of anti-Glycine receptor antibodies. Although GAD antibodies have not been demonstrated to be pathogenic, the anti-Glycine receptor antibodies seem to be $[134,135]$. Dysphagia can be present in both PERM and SPS, especially when bulbar, brainstem, or cerebellar symptoms are prominent as seen in at least $15 \%$ of patients [132-134]. In our experience with a large number of SPS-SD, dysphagia can be a debilitating symptom, especially in patients with co-existing cerebellar ataxia and is often accompanied by dysphonia.

The treatment of dysphagia in SPS-SD and PERM includes symptomatic therapies with GABA-enhancing drugs, such as benzodiazepines, baclofen or gabapentin, and immunotherapy with IVIg or rituximab [131]. In a controlled trial of SPS patients, IVIg was effective and is now the treatment of choice [136]. A controlled trial with rituximab did not, however, show statistically significant differences owing to a strong placebo effect, but a subset of SPS patients exhibited strong and sustained improvements [137].

\section{Autoimmune Encephalitides}

In autoimmune encephalitides, dysphagia can be present, although this association is often confounded by impaired level of consciousness. Clinical dysphagia has been reported in several acute encephalitides including (a) those with antibodies to synaptic antigens such as NMDAR and Gamma Aminobutyric Acid receptor B (GABAR-B) antibodies; (b) acute disseminated encephalomyelitis (ADEM) as part of a bilateral opercular syndrome, also described as Foix-Chavany-Marie syndrome, where paralysis of facial, tongue, pharyngeal, and masticatory muscles can be prominent $[138,139]$ (c) Chronic Lymphocytic Inflammation with Pontine Perivascular Enhancement Responsive to Steroids (CLIPPERS) [140, 141]; (d) Dipeptidyl Peptidase-like Protein-6 (DPPX)-autoantibody-associated disease with prominent gastrointestinal dysmotility [142]; (e) Hashimoto encephalopathy [143]; (f) Bickerstaff brainstem encephalitis $[144,145]$, and $(\mathrm{g})$ the recently identified disease characterized by autoantibodies against the brain neuronal adhesion molecule IgLON5, which presents with a bulbar syndrome that includes (as often as 50-86\% of cases) dysphagia, along with sleep disturbances (parasomnias, difficulty breathing), cognitive decline, and progressive supranuclear palsy-like symptoms [146, 147]. Dysphagia can be also seen within the clinical spectrum of several, predominantly paraneoplastic, autoimmune CNS syndromes, characterized by autoantibodies against intracellular antigens such as $\mathrm{Hu}, \mathrm{Ri}$, neurochondrin, Glial Fibrillary Acidic Protein (GFAP), Ma antigen-2 (Ma2), or Rho GTPase-activating protein 26 [80, 148-151]. In all those entities dysphagia treatment includes immunotherapy, which can be variably effective.

\section{Summary and Conclusion}

Dysphagia is part of the clinical spectrum of various autoimmune neurological disorders affecting the whole neuraxis (muscle, neuromuscular junction, nerve, roots, brainstem and cortical regions), occurring either alone or in combination with other symptoms. Awareness of the causative factors and early clinical manifestations of autoimmune neurogenic dysphagia are important because prompt initiation of immunotherapy is an effective means of alleviating dysphagic symptoms. Dysphagia can be manifested insidiously in the presence of an existing autoimmune neurological disease, but it can also present acutely or subacutely as the early manifestation of an evolving neuro-autoimmunity. In inflammatory myopathies, dysphagia most commonly occurs in IBM, but it is not uncommon in DM, anti-SS$\mathrm{OM}$, and NAM/IMNM; an elevated CK raises suspicion, and a muscle biopsy confirms the diagnosis. While immunotherapy is generally effective, IBM remains still difficult to treat. In MG, dysphagia is often associated with fatigability and other cranial nerve involvement; when diagnosis is confirmed by detection of specific autoantibodies, dysphagia has an impressive response to immunotherapy. In autoimmune neuropathies, acute-onset dysphagia as seen in PCB, MFS and GBS variants, should be recognized and treated early to optimize outcome; more insidious dysphagia is seen in paraneoplastic neuropathies, highlighted by anti-Hu/-Ri autoantibodies and in ganglionopathies associated with autonomic dysfunction, gastrointestinal dysmotility, and antibodies to gAChR or VGCC. In paraneoplastic syndromes, although symptoms can be more difficult to treat, response to immunotherapy is variable but more promising in the presence of pathogenic autoantibodies against surface proteins. Among the CNS causes of autoimmune neurogenic dysphagia are demyelinating and inflammatory lesions of the brainstem, usually in the setting of advanced MS and NMO-SDs associated with autoantibodies against AQP4 and MOG, where early diagnosis is of paramount importance as response to immunotherapy can be rewarding. Autoimmune hyperexcitability disorders, highlighted by the SPS-SDs that typically present with hyperexcitability, spasms, and high-titer antiGAD autoantibodies, are overlooked causes of potentially treatable autoimmune dysphagia. Considering the multitude 
of neurological autoimmune disorders and their disease mimics causing dysphagia, increased awareness is critical to establish the correct diagnosis and initiate immunotherapy as most of the underlying neurological disorders are potentially treatable.

Funding The authors did not receive support from any organization for the submitted work. No funding was received to assist with the preparation of this manuscript.

\section{Declarations}

Conflict of interest The authors have no relevant financial or non-financial interests to disclose.

Ethical Approval This material is the authors' own original work, which has not been previously published or considered for publication elsewhere. The paper properly credits the meaningful contributions of co-authors and co-researchers. All sources used are properly disclosed. All authors have been personally and actively involved in substantial work leading to the paper and will take public responsibility for its content.

Open Access This article is licensed under a Creative Commons Attribution 4.0 International License, which permits use, sharing, adaptation, distribution and reproduction in any medium or format, as long as you give appropriate credit to the original author(s) and the source, provide a link to the Creative Commons licence, and indicate if changes were made. The images or other third party material in this article are included in the article's Creative Commons licence, unless indicated otherwise in a credit line to the material. If material is not included in the article's Creative Commons licence and your intended use is not permitted by statutory regulation or exceeds the permitted use, you will need to obtain permission directly from the copyright holder. To view a copy of this licence, visit http://creativecommons.org/licenses/by/4.0/.

\section{References}

1. Dalakas MC, Hohlfeld R. Polymyositis and dermatomyositis. Lancet. 2003;362:971-82.

2. Dalakas MC. Polymyositis, dermatomyositis, and inclusion-body myositis. N Engl J Med. 1991;325:1487-98.

3. Dalakas MC. Inflammatory muscle diseases. N Engl J Med. 2015;372:1734-47.

4. Love LA, Leff RL, Fraser DD, Targoff IN, Dalakas M, Plotz $\mathrm{PH}$, et al. A new approach to the classification of idiopathic inflammatory myopathy: myositis-specific autoantibodies define useful homogeneous patient groups. Medicine (Baltimore). 1991;70:360-74.

5. Labeit B, Pawlitzki M, Ruck T, Muhle P, Claus I, Suntrup-Krueger $\mathrm{S}$, et al. The impact of dysphagia in myositis: a systematic review and meta-analysis. JCM. 2020;9:2150.

6. Dobloug C, Garen T, Bitter H, Stjärne J, Stenseth G, Grøvle L, et al. Prevalence and clinical characteristics of adult polymyositis and dermatomyositis; data from a large and unselected Norwegian cohort. Ann Rheum Dis. 2015;74:1551-6.

7. Ríos G. Retrospective review of the clinical manifestations and outcomes in puerto ricans with idiopathic inflammatory myopathies. JCR J Clin Rheumatol. 2005;11:153-6.
8. Wolstencroft PW, Fiorentino DF. Dermatomyositis clinical and pathological phenotypes associated with myositis-specific autoantibodies. Curr Rheumatol Rep. 2018;20:28.

9. Sheehan NJ. Dysphagia and other manifestations of oesophageal involvement in the musculoskeletal diseases. Rheumatology. $2008 ; 47: 746-52$.

10. Lilleker JB, Vencovsky J, Wang G, Wedderburn LR, Diederichsen LP, Schmidt J, et al. The EuroMyositis registry: an international collaborative tool to facilitate myositis research. Ann Rheum Dis. 2018;77:30-9.

11. Oh TH, Brumfield KA, Hoskin TL, Stolp KA, Murray JA, Basford JR. Dysphagia in inflammatory myopathy: clinical characteristics, treatment strategies, and outcome in 62 patients. Mayo Clin Proc. 2007;82:441-7.

12. Triplett JD, Pinto MV, Hosfield EA, Milone M, Liewluck T. Myopathies featuring early or prominent dysphagia. Muscle Nerve. 2020;62:344-50.

13. Dalakas MC, Illa I, Dambrosia JM, Soueidan SA, Stein DP, Otero C, et al. A controlled trial of high-dose intravenous immune globulin infusions as treatment for dermatomyositis. N Engl J Med. 1993;329:1993-2000.

14. Dalakas MC. Necrotising autoimmune myopathy (NAM): antibodies seem to be specific markers in aiding diagnosis. $\mathbf{J}$ Neurol Neurosurg Psychiatry. 2016;87:1037.

15. Dalakas MC. Are autoantibodies pathogenic in necrotizing myopathy? Nat Rev Rheumatol. 2018;14:251-2.

16. Dalakas MC. Case 22-2019: a 65-year-old woman with myopathy. N Engl J Med. 2019;381:1693.

17. Cox FM, Titulaer MJ, Sont JK, Wintzen AR, Verschuuren JJGM, Badrising UA. A 12-year follow-up in sporadic inclusion body myositis: an end stage with major disabilities. Brain. 2011;134:3167-75.

18. Taira K, Yamamoto T, Mori-Yoshimura M, Fujita S, Oya Y, Nishino I, et al. Obstruction-related dysphagia in inclusion body myositis: cricopharyngeal bar on videofluoroscopy indicates risk of aspiration. J Neurol Sci. 2020;413:116764.

19. Cox FM, Verschuuren JJ, Verbist BM, Niks EH, Wintzen AR, Badrising UA. Detecting dysphagia in inclusion body myositis. J Neurol. 2009;256:2009-13.

20. Houser SM, Calabrese LH, Strome M. Dysphagia in patients with inclusion body myositis. Laryngoscope. 1998;108:1001-5.

21. Dalakas MC, Sonies B, Dambrosia J, Sekul E, Cupler E, Sivakumar K. Treatment of inclusion-body myositis with IVIg: a double-blind, placebo-controlled study. Neurology. 1997;48:712-6.

22. Wintzen AR, Bots GT, de Bakker HM, Hulshof JH, Padberg GW. Dysphagia in inclusion body myositis. J Neurol Neurosurg Psychiatry. 1988;51:1542-5.

23. Riminton DS, Chambers ST, Parkin PJ, Pollock M, Donaldson IM. Inclusion body myositis presenting solely as dysphagia. Neurology. 1993;43:1241-1.

24. Lotz BP, Engel AG, Nishino H, Stevens JC, Litchy WJ. Inclusion body myositis: observations in 40 patients. Brain. 1989;112:727-47.

25. Dalakas MC, Rakocevic G, Schmidt J, Salajegheh M, McElroy B, Harris-Love MO, et al. Effect of Alemtuzumab (CAMPATH 1-H) in patients with inclusion-body myositis. Brain. 2009; 132:1536-44.

26. Kosmidis ML, Pikazis D, Vlachoyiannopoulos P, Tzioufas AG, Dalakas MC. Trial of canakinumab, an IL-1 $\beta$ receptor antagonist, in patients with inclusion body myositis. Neurol Neuroimmunol Neuroinflamm. 2019;6:e581.

27. Kosmidis ML, Alexopoulos H, Tzioufas AG, Dalakas MC. The effect of anakinra, an IL1 receptor antagonist, in patients with 
sporadic inclusion body myositis (sIBM): a small pilot study. $\mathrm{J}$ Neurol Sci. 2013;334:123-5.

28. Zong M, Dorph C, Dastmalchi M, Alexanderson H, Pieper J, Amoudruz $\mathrm{P}$, et al. Anakinra treatment in patients with refractory inflammatory myopathies and possible predictive response biomarkers: a mechanistic study with 12 months follow-up. Ann Rheum Dis. 2014;73:913-20.

29. McMillan RA, Bowen AJ, Bayan SL, Kasperbauer JL, Ekbom DC. Cricopharyngeal myotomy in inclusion body myositis: comparison of endoscopic and transcervical approaches. Laryngoscope. 2021. https://doi.org/10.1002/lary.29444.

30. Oh TH, Brumfield KA, Hoskin TL, Kasperbauer JL, Basford JR. Dysphagia in inclusion body myositis: clinical features, management, and clinical outcome. Am J Phys Med Rehabil. 2008;87:883-9.

31. Murata K, Kouda K, Tajima F, Kondo T. Balloon dilation in sporadic inclusion body myositis patients with dysphagia. Clin Med Insights Case Rep. 2013;6:CCRep.S10200.

32. Mohannak N, Pattison G, Hird K, Needham M. Dysphagia in patients with sporadic inclusion body myositis: management challenges. IJGM. 2019;12:465-74.

33. Zeng R, Schmidt J. Impact and management of dysphagia in inflammatory myopathies. Curr Rheumatol Rep. 2020;22:74.

34. Peng A, Koffman BM, Malley JD, Dalakas MC. Disease progression in sporadic inclusion body myositis: observations in 78 patients. Neurology. 2000;55:296-8.

35. Lindstrom JM. Acetylcholine receptors and myasthenia. Muscle Nerve. 2000;23:453-77.

36. Hoch W, McConville J, Helms S, Newsom-Davis J, Melms A, Vincent A. Auto-antibodies to the receptor tyrosine kinase MuSK in patients with myasthenia gravis without acetylcholine receptor antibodies. Nat Med. 2001;7:365-8.

37. Verschuuren J, Strijbos E, Vincent A. Neuromuscular junction disorders. Handbook of Clinical Neurology [Internet]. Elsevier; 2016 [cited 2020 Sep 21]. p. 447-66. Available from: https://linki nghub.elsevier.com/retrieve/pii/B9780444634320000244

38. Sanders DB, El-Salem K, Massey JM, McConville J, Vincent A. Clinical aspects of MuSK antibody positive seronegative MG. Neurology. 2003;60:1978-80.

39. Murray JP. Deglutition in myasthenia gravis. BJR. 1962:35:43-52.

40. Llabres M. Dysphagia as the sole manifestation of myasthenia gravis. J Neurol Neurosurg Psychiatry. 2005;76:1297-300.

41. Huang MH, King KL, Chien KY. Esophageal manometric studies in patients with myasthenia gravis. J Thorac Cardiovasc Surg. 1988;95:281-5.

42. Grob D, Arsura EL, Brunner NG, Namba T. The course of myasthenia gravis and therapies affecting outcome. Ann NY Acad Sci. 1987;505:472-99.

43. Emilia-Romagna Study Group on Clinical and Epidemiological Problems in Neurology*. Incidence of myasthenia gravis in the Emilia-Romagna region: A prospective multicenter study. Neurology. 1998;51: 255-8.

44. Carpenter RJ, Mcdonald TJ, Howard FM. The otolaryngologic presentation of myasthenia gravis. Laryngoscope. 1979;89:922???928.

45. Arellano-Aguilar G, Núñez-Mojica ES, Gutiérrez-Velazco JL, Domínguez-Carrillo LG. Paraneoplastic Lambert-Eaton syndrome in a patient with disseminated metastatic cancer. CIRUE. 2019;86:1948.

46. Dalakas MC. Immunotherapy in myasthenia gravis in the era of biologics. Nat Rev Neurol. 2019;15:113-24.

47. Dalakas MC. Experience with IVIg in the treatment of patients with myasthenia gravis. Neurology. 1997;48:64S-9S.
48. Dalakas MC, Alexopoulos H, Spaeth PJ. Complement in neurological disorders and emerging complement-targeted therapeutics. Nat Rev Neurol. 2020;16:601-17.

49. Lünemann JD, Quast I, Dalakas MC. Efficacy of intravenous immunoglobulin in neurological diseases. Neurotherapeutics. 2016;13:34-46.

50. Fisher M. An unusual variant of acute idiopathic polyneuritis (syndrome of ophthalmoplegia, ataxia and areflexia). N Engl J Med. 1956;255:57-65.

51. Nagashima T, Koga M, Odaka M, Hirata K, Yuki N. Continuous spectrum of pharyngeal-cervical-brachial variant of GuillainBarré syndrome. Arch Neurol. 2007;64:1519-23.

52. Wakerley BR, Yuki N. Pharyngeal-cervical-brachial variant of Guillain-Barre syndrome. J Neurol Neurosurg Psychiatry. 2014;85:339-44.

53. Arakawa M, Yamazaki M, Toda Y, Ozawa A, Kimura K. An oculopharyngeal subtype of Guillain-Barré syndrome sparing the trochlear and abducens nerves. Intern Med. 2020;59:1215-7.

54. Patel K, Nussbaum E, Sico J, Merchant N. Atypical case of Miller-Fisher syndrome presenting with severe dysphagia and weight loss. BMJ Case Rep. 2020;13:e234316.

55. Edvardsson B, Persson S. Polyneuritis cranialis presenting with anti-GQ1b IgG antibody. J Neurol Sci. 2009;281:125-6.

56. Ilyas AA, Cook SD, Mithen FA, Taki T, Kasama T, Handa S, et al. Antibodies to GT1a ganglioside in patients with GuillainBarré syndrome. J Neuroimmunol. 1998;82:160-7.

57. Dirlikov E, Major CG, Medina NA, Lugo-Robles R, Matos D, Muñoz-Jordan JL, et al. Clinical features of Guillain-Barré syndrome with vs without Zika virus infection, Puerto Rico, 2016. JAMA Neurol. 2018;75:1089.

58. Orlikowski D, Terzi N, Blumen M, Sharshar T, Raphael JC, Annane D, et al. Tongue weakness is associated with respiratory failure in patients with severe Guillain-Barré syndrome. Acta Neurol Scand. 2009;119:364-70.

59. Chen MYM, Donofrio PD, Frederick MG, Ott DJ, Pikna LA. Videofluoroscopic evaluation of patients with Guillain-Barré syndrome. Dysphagia. 1996;11:11-3.

60. Mengi T, Seçil Y, İncesu TK, Arici Ş, Akkiraz ZÖ, Gürgör N, et al. Guillain-Barré syndrome and swallowing dysfunction. J Clin Neurophysiol. 2017;34:393-9.

61. Dalakas MC. Guillain-Barré syndrome: the first documented COVID-19-triggered autoimmune neurologic disease: more to come with myositis in the offing. Neurol Neuroimmunol Neuroinflamm. 2020;7:e781.

62. Costello F, Dalakas MC. Cranial neuropathies and COVID-19: Neurotropism and autoimmunity. Neurology. 2020;95:195-6.

63. Hughes RA, Swan AV, van Doorn PA. Intravenous immunoglobulin for Guillain-Barré syndrome. In: The Cochrane Collaboration, editor. Cochrane Database of Systematic Reviews [Internet]. Chichester, UK: John Wiley \& Sons, Ltd; 2010 [cited 2020 Sep 27]. p. CD002063.pub4. Available from: http://doi. wiley.com/https://doi.org/10.1002/14651858.CD002063.pub4

64. Dalakas MC. Intravenous immunoglobulin in autoimmune neuromuscular diseases. JAMA. 2004;291:2367-75.

65. Teramoto H, Morita A, Hara M, Ninomiya S, Shigihara S, Kusunoki S, et al. Relapse with dysphagia in a case of chronic inflammatory demyelinating polyradiculoneuropathy. Intern Med. 2015;54:1791-3.

66. Mazzucco S, Ferrari S, Mezzina C, Tomelleri G, Bertolasi L, Rizzuto N. Hyperpyrexia-triggered relapses in an unusual case of ataxic chronic inflammatory demyelinating polyradiculoneuropathy. Neurol Sci. 2006;27:176-9.

67. Querol L, Rojas-García R, Diaz-Manera J, Barcena J, Pardo J, Ortega-Moreno A, et al. Rituximab in treatment-resistant CIDP with antibodies against paranodal proteins. Neurol Neuroimmunol Neuroinflamm. 2015;2:e149. 
68. van Schaik IN, Bril V, van Geloven N, Hartung H-P, Lewis RA, Sobue G, et al. Subcutaneous immunoglobulin for maintenance treatment in chronic inflammatory demyelinating polyneuropathy (PATH): a randomised, double-blind, placebo-controlled, phase 3 trial. Lancet Neurol. 2018;17:35-46.

69. Bedi G, Brown A, Tong T, Sharma KR. Chronic inflammatory demyelinating polyneuropathy responsive to mycophenolate mofetil therapy. J Neurol Neurosurg Psychiatry. 2010;81:634-6.

70. Dyck PJ, O'Brien P, Swanson C, Low P, Daube J. Combined azathioprine and prednisone in chronic inflammatory-demyelinating polyneuropathy. Neurology. 1985;35:1173-6.

71. Baehring JM, Batchelor TT. Diagnosis and management of neurolymphomatosis. Cancer J. 2012;18:463-8.

72. Zekeridou A, Lennon VA. Neurologic autoimmunity in the era of checkpoint inhibitor cancer immunotherapy. Mayo Clin Proc. 2019;94:1865-78.

73. Dalakas MC. Neurological complications of immune checkpoint inhibitors: what happens when you "take the brakes off" the immune system. Ther Adv Neurol Disord. 2018;11:1756286418799864.

74. Muppidi S, Vernino S. Paraneoplastic neuropathies. Continuum (Minneap Minn). 2014;20:1359-72.

75. Graus F, Dalmau J. Paraneoplastic neuropathies. Curr Opin Neurol. 2013;26:489-95.

76. Antoine JC, Mosnier JF, Absi L, Convers P, Honnorat J, Michel D. Carcinoma associated paraneoplastic peripheral neuropathies in patients with and without anti-onconeural antibodies. J Neurol Neurosurg Psychiatry. 1999;67:7-14.

77. Viala K, Béhin A, Maisonobe T, Léger J-M, Stojkovic T, Davi F, et al. Neuropathy in lymphoma: a relationship between the pattern of neuropathy, type of lymphoma and prognosis? J Neurol Neurosurg Psychiatry. 2008;79:778-82.

78. Ni J, Weng L, Liu M, Yang H, Wang Y. Small cell lung cancer accompanied by tonsillar metastasis and anti-hu antibody-associated paraneoplastic neuropathy: a rare case report with long-term survival. Medicine. 2015;94:e2291.

79. Yeung JC, Pringle CE, Sekhon HS, Kilty SJ, Macdonald K. Bilateral vocal cord paralysis and cervicolumbar radiculopathy as the presenting paraneoplastic manifestations of small cell lung cancer: a case report and literature review. Case Rep Otolaryngol. 2016;2016:1-5.

80. Pittock SJ, Lucchinetti CF, Lennon VA. Anti-neuronal nuclear autoantibody type 2: paraneoplastic accompaniments. Ann Neurol. 2003;53:580-7.

81. Terushkin V, Stern BJ, Judson MA, Hagiwara M, Pramanik B, Sanchez M, et al. Neurosarcoidosis: presentations and management. Neurologist. 2010;16:2-15.

82. Brito-Zerón P, Bari K, Baughman RP, Ramos-Casals M. Sarcoidosis involving the gastrointestinal tract: diagnostic and therapeutic management. Am J Gastroenterol. 2019;114:1238-47.

83. Nishikubo K, Hyodo M, Kawakami M, Kobayashi T. A rare manifestation of cricopharyngeal myopathy presenting with dysphagia in sarcoidosis. Rheumatol Int. 2013;33:1089-92.

84. Zella S, Kneiphof J, Haghikia A, Gold R, Woitalla D, Thöne J. Successful therapy with rituximab in three patients with probable neurosarcoidosis. Ther Adv Neurol Disord. 2018;11:1756286418805732.

85. Pavlakis PP, Alexopoulos H, Kosmidis ML, Mamali I, Moutsopoulos HM, Tzioufas AG, et al. Peripheral neuropathies in Sjögren's syndrome: a critical update on clinical features and pathogenetic mechanisms. J Autoimmun. 2012;39:27-33.

86. Pavlakis PP, Alexopoulos H, Kosmidis ML, Stamboulis E, Routsias JG, Tzartos SJ, et al. Peripheral neuropathies in Sjogren syndrome: a new reappraisal. J Neurol Neurosurg Psychiatry. 2011;82:798-802.
87. Florica B, Aghdassi E, Su J, Gladman DD, Urowitz MB, Fortin PR. Peripheral neuropathy in patients with systemic lupus erythematosus. Semin Arthritis Rheum. 2011;41:203-11.

88. Edmonds ME, Jones TC, Saunders WA, Sturrock RD. Autonomic neuropathy in rheumatoid arthritis. Br Med J. 1979;2:173-5.

89. Poglio F, Mongini T, Cocito D. Sensory ataxic neuropathy and esophageal achalasia in a patient with Sjogren's syndrome. Muscle Nerve. 2007;35:532-5.

90. Sanchez JMS, McNally JS, Cortez MM, Hemp J, Pace LA, Clardy SL. Neuroimmunogastroenterology: at the interface of neuroimmunology and gastroenterology. Front Neurol. 2020;11:787.

91. Dhamija R, Tan KM, Pittock SJ, Foxx-Orenstein A, Benarroch E, Lennon VA. Serologic profiles aiding the diagnosis of autoimmune gastrointestinal dysmotility. Clin Gastroenterol Hepatol. 2008;6:988-92.

92. Mukaino A, Minami H, Isomoto H, Hamamoto H, Ihara E, Maeda $\mathrm{Y}$, et al. Anti-ganglionic AChR antibodies in Japanese patients with motility disorders. J Gastroenterol. 2018;53:1227-40.

93. D’Amico E, Zanghì A, Serra A, Murabito P, Zappia M, Patti F, et al. Management of dysphagia in multiple sclerosis: current best practice. Expert Rev Gastroenterol Hepatol. 2019;13:47-54.

94. Tassorelli C, Bergamaschi R, Buscone S, Bartolo M, Furnari A, Crivelli $\mathrm{P}$, et al. Dysphagia in multiple sclerosis: from pathogenesis to diagnosis. Neurol Sci. 2008;29:360-3.

95. Pender MP, Ferguson SM. Dysarthria and dysphagia due to the opercular syndrome in multiple sclerosis. Mult Scler. 2007;13:817-9.

96. Guan X-L, Wang H, Huang H-S, Meng L. Prevalence of dysphagia in multiple sclerosis: a systematic review and meta-analysis. Neurol Sci. 2015;36:671-81.

97. Shibasaki H, McDonald WI, Kuroiwa Y. Racial modification of clinical picture of multiple sclerosis: comparison between British and Japanese patients. J Neurol Sci. 1981;49:253-71.

98. Hartelius L, Svensson P. Speech and swallowing symptoms associated with Parkinson's disease and multiple sclerosis: a survey. Folia Phoniatr Logop. 1994;46:9-17.

99. Levinthal DJ, Rahman A, Nusrat S, O’Leary M, Heyman R, Bielefeldt K. Adding to the burden: gastrointestinal symptoms and syndromes in multiple sclerosis. Mult Scler Int. 2013;2013:1-9.

100. Solaro C, Rezzani C, Trabucco E, Amato MP, Zipoli V, Portaccio E, et al. Prevalence of patient-reported dysphagia in multiple sclerosis patients: an Italian multicenter study (using the DYMUS questionnaire). J Neurol Sci. 2013;331:94-7.

101. Danesh-Sani SA, Rahimdoost A, Soltani M, Ghiyasi M, Haghdoost N, Sabzali-Zanjankhah S. Clinical assessment of orofacial manifestations in 500 patients with multiple sclerosis. J Oral Maxillofac Surg. 2013;71:290-4.

102. Abraham S, Scheinberg LC, Smith CR, LaRocca NG. Neurologic impairment and disability status in outpatients with multiple sclerosis reporting dysphagia symptomatology. Neurorehabil Neural Repair. 1997;11:7-13.

103. De Pauw A, Dejaeger E, D'hooghe B, Carton H. Dysphagia in multiple sclerosis. Clin Neurol Neurosurg. 2002;104:345-51.

104. Fernandes AMF, de Campos DA, Eckley CA, da Silva L, Ferreira $\mathrm{RB}$, Tilbery CP. Oropharyngeal dysphagia in patients with multiple sclerosis: do the disease classification scales reflect dysphagia severity? Braz J Otorhinolaryngol. 2013;79:460-5.

105. Alfonsi E, Bergamaschi R, Cosentino G, Ponzio M, Montomoli C, Restivo DA, et al. Electrophysiological patterns of oropharyngeal swallowing in multiple sclerosis. Clin Neurophysiol. 2013;124:1638-45.

106. Wiesner W, Wetzel SG, Kappos L, Hoshi MM, Witte U, Radue $\mathrm{EW}$, et al. Swallowing abnormalities in multiple sclerosis: 
correlation between videofluoroscopy and subjective symptoms. Eur Radiol. 2002;12:789-92.

107. Terré-Boliart R, Orient-López F, Guevara-Espinosa D, RamónRona S, Bernabeu-Guitart M. Clavé-Civit P [Oropharyngeal dysphagia in patients with multiple sclerosis]. Rev Neurol. 2004;39:707-10.

108. Oh J, Vidal-Jordana A, Montalban X. Multiple sclerosis: clinical aspects. Curr Opin Neurol. 2018;31:752-9.

109. Stankiewicz JM, Weiner HL. An argument for broad use of high efficacy treatments in early multiple sclerosis. Neurol Neuroimmunol Neuroinflamm. 2020;7:e636.

110. He A, Merkel B, Brown JWL, Zhovits Ryerson L, Kister I, Malpas CB, et al. Timing of high-efficacy therapy for multiple sclerosis: a retrospective observational cohort study. Lancet Neurol. 2020;19:307-16.

111. Restivo DA, Marchese-Ragona R, Patti F. Management of swallowing disorders in multiple sclerosis. Neurol Sci. 2006;27:s338-40.

112. Lennon VA, Kryzer TJ, Pittock SJ, Verkman AS, Hinson SR. IgG marker of optic-spinal multiple sclerosis binds to the aquaporin-4 water channel. J Exp Med. 2005;202:473-7.

113. O'Connor KC, McLaughlin KA, De Jager PL, Chitnis T, Bettelli E, Xu C, et al. Self-antigen tetramers discriminate between myelin autoantibodies to native or denatured protein. Nat Med. 2007; 13:211-7.

114. Chan KH. Brain involvement in neuromyelitis optica spectrum disorders. Arch Neurol. 2011;68:1432.

115. Koda A, Kaneko S, Asayama S, Fujita K, Kusaka H. Successful treatment of neuromyelitis optica spectrum disorder by early initiation of plasma exchange. Rinsho Shinkeigaku. 2015;55:41-4.

116. Cousins O, Girelli E, Harikrishnan S. Neuromyelitis optica: an elusive cause of dysphagia. BMJ Case Rep. 2019;12:bcr-2018-227041.

117. Takahashi T, Miyazawa I, Misu T, Takano R, Nakashima I, Fujihara K, et al. Intractable hiccup and nausea in neuromyelitis optica with anti-aquaporin-4 antibody: a herald of acute exacerbations. J Neurol Neurosurg Psychiatry. 2008;79:1075-8.

118. Wingerchuk DM, Banwell B, Bennett JL, Cabre P, Carroll $\mathrm{W}$, Chitnis T, et al. International consensus diagnostic criteria for neuromyelitis optica spectrum disorders. Neurology. 2015;85:177-89.

119. Hillebrand S, Schanda K, Nigritinou M, Tsymala I, Böhm D, Peschl P, et al. Circulating AQP4-specific auto-antibodies alone can induce neuromyelitis optica spectrum disorder in the rat. Acta Neuropathol. 2019;137:467-85.

120. Ratelade J, Bennett JL, Verkman AS. Intravenous neuromyelitis optica autoantibody in mice targets aquaporin- 4 in peripheral organs and area postrema. PLoS ONE. 2011;6:e27412.

121. Wang Y, Zhang L, Zhang B, Dai Y, Kang Z, Lu C, et al. Comparative clinical characteristics of neuromyelitis optica spectrum disorders with and without medulla oblongata lesions. J Neurol. 2014;261:954-62.

122. Pawlitzki M, Ahring S, Rolfes L, Dziewas R, Warnecke T, Suntrup-Krueger S, et al. Dysphagia in NMOSD and MOGAD as a surrogate of brain involvement? Eur J Neurol. 2020; ene.14691. https://doi.org/10.1111/ene.14691.

123. Sonies BC, Dalakas MC. Dysphagia in patients with the postpolio syndrome. N Engl J Med. 1991;324:1162-7.

124. Huh S-Y, Kim S-H, Hyun J-W, Joung A-R, Park MS, Kim B-J, et al. Mycophenolate mofetil in the treatment of neuromyelitis optica spectrum disorder. JAMA Neurol. 2014;71:1372.

125. Kim S-H, Jeong IH, Hyun J-W, Joung A, Jo H-J, Hwang S-H, et al. Treatment outcomes with rituximab in 100 patients with neuromyelitis optica: influence of FCGR3A polymorphisms on the therapeutic response to rituximab. JAMA Neurol 2015;72:989.

126. Cree BAC, Bennett JL, Kim HJ, Weinshenker BG, Pittock SJ, Wingerchuk DM, et al. Inebilizumab for the treatment of neuromyelitis optica spectrum disorder (N-MOmentum): a doubleblind, randomised placebo-controlled phase $2 / 3$ trial. Lancet. 2019;394:1352-63.

127. Pittock SJ, Berthele A, Fujihara K, Kim HJ, Levy M, Palace J, et al. Eculizumab in aquaporin-4-positive neuromyelitis optica spectrum disorder. N Engl J Med. 2019;381:614-25.

128. Chalmoukou K, Alexopoulos H, Akrivou S, Stathopoulos P, Reindl M, Dalakas MC. Anti-MOG antibodies are frequently associated with steroid-sensitive recurrent optic neuritis. Neurol Neuroimmunol Neuroinflamm. 2015;2:e131.

129. Whittam DH, Cobo-Calvo A, Lopez-Chiriboga AS, Pardo S, Gornall M, Cicconi S, et al. Treatment of MOG-IgG-associated disorder with rituximab: an international study of 121 patients. Mult Scler Relat Disord. 2020;44:102251.

130. Jarius S, Ruprecht K, Kleiter I, Borisow N, Asgari N, Pitarokoili $\mathrm{K}$, et al. MOG-IgG in NMO and related disorders: a multicenter study of 50 patients. Part 2: epidemiology, clinical presentation, radiological and laboratory features, treatment responses, and long-term outcome. J Neuroinflamm. 2016;13:280.

131. Tsiortou P, Alexopoulos H, Dalakas MC. GAD antibody-spectrum disorders: progress in clinical phenotypes, immunopathogenesis and therapeutic interventions. Ther Adv Neurol Disord. 2021;14:17562864211003486.

132. Rakocevic G, Alexopoulos H, Dalakas MC. Quantitative clinical and autoimmune assessments in stiff person syndrome: evidence for a progressive disorder. BMC Neurol. 2019;19:1.

133. Rakocevic G, Raju R, Semino-Mora C, Dalakas MC. Stiff person syndrome with cerebellar disease and high-titer anti-GAD antibodies. Neurology. 2006;67:1068-70.

134. Carvajal-González A, Leite MI, Waters P, Woodhall M, Coutinho E, Balint B, et al. Glycine receptor antibodies in PERM and related syndromes: characteristics, clinical features and outcomes. Brain. 2014;137:2178-92.

135. Alexopoulos H, Akrivou S, Dalakas MC. Glycine receptor antibodies in stiff-person syndrome and other GAD-positive CNS disorders. Neurology. 2013;81:1962-4.

136. Dalakas MC, Fujii M, Li M, Lutfi B, Kyhos J, McElroy B. Highdose intravenous immune globulin for stiff-person syndrome. $\mathrm{N}$ Engl J Med. 2001;345:1870-6.

137. Dalakas MC, Rakocevic G, Dambrosia JM, Alexopoulos H, McElroy B. A double-blind, placebo-controlled study of rituximab in patients with stiff person syndrome. Ann Neurol. 2017;82:271-7.

138. RamachandranNair R, Manoj P, Rafeequ M, Girija AS. Childhood acute disseminated encephalomyelitis presenting as FoixChavany-Marie syndrome. J Child Neurol. 2005;20:163-5.

139. Pittard A, Abramo TJ, Arnold DH. A child with difficulty swallowing. Pediatr Emerg Care. 2009;25:525-8.

140. Ma Y, Sun X, Li W, Li Y, Kang T, Yang X, et al. Chronic lymphocytic inflammation with pontine perivascular enhancement responsive to steroids (CLIPPERS) with intracranial EpsteinBarr virus infection: a case report. Medicine. 2016;95:e5377.

141. Mundiyanapurath S, Jarius S, Probst C, Stöcker W, Wildemann B, Bösel J. GABA-B-receptor antibodies in paraneoplastic brainstem encephalitis. J Neuroimmunol. 2013;259:88-91.

142. Tobin WO, Lennon VA, Komorowski L, Probst C, Clardy SL, Aksamit AJ, et al. DPPX potassium channel antibody: frequency, clinical accompaniments, and outcomes in 20 patients. Neurology. 2014;83:1797-803. 
143. Oz Tuncer G, Teber S, Kutluk MG, Albayrak P, Deda G. Hashimoto's encephalopathy presenting as pseudobulbar palsy. Childs Nerv Syst. 2018;34:1251-4.

144. Odaka M, Yuki N, Yamada M, Koga M, Takemi T, Hirata K, et al. Bickerstaff's brainstem encephalitis: clinical features of 62 cases and a subgroup associated with Guillain-Barré syndrome. Brain. 2003;126:2279-90.

145. Michev A, Musso P, Foiadelli T, Trabatti C, Lozza A, Franciotta D, et al. Bickerstaff brainstem encephalitis and overlapping Guillain-Barré syndrome in children: report of two cases and review of the literature. Eur J Paediatr Neurol. 2019;23:43-52.

146. Gaig C, Graus F, Compta Y, Högl B, Bataller L, Brüggemann N, et al. Clinical manifestations of the anti-IgLON5 disease. Neurology. 2017;88:1736-43.

147. Honorat JA, Komorowski L, Josephs KA, Fechner K, St Louis EK, Hinson SR, et al. IgLON5 antibody: neurological accompaniments and outcomes in 20 patients. Neurol Neuroimmunol Neuroinflamm. 2017;4:e385.

148. Li X-L, Han J, Zhao H-T, Long Y-M, Zhang B-W, Wang H-Y. Autoimmune glial fibrillary acidic protein astrocytopathy with lesions distributed predominantly in the entire spinal cord. Ther Adv Neurol Disord. 2020;13:175628642090997.
149. Shelly S, Kryzer TJ, Komorowski L, Miske R, Anderson MD, Flanagan EP, et al. Neurochondrin neurological autoimmunity. Neurol Neuroimmunol Neuroinflamm. 2019;6:e612.

150. Wallwitz U, Brock S, Schunck A, Wildemann B, Jarius S, Hoffmann F. From dizziness to severe ataxia and dysarthria: New cases of anti-Ca/ARHGAP26 autoantibody-associated cerebellar ataxia suggest a broad clinical spectrum. J Neuroimmunol. 2017;309:77-81.

151. Castle J, Sakonju A, Dalmau J, Newman-Toker DE. Anti-Ma2associated encephalitis with normal FDG-PET: a case of pseudoWhipple's disease. Nat Rev Neurol. 2006;2:566-72.

Publisher's Note Springer Nature remains neutral with regard to jurisdictional claims in published maps and institutional affiliations.

Panos Stathopoulos MD

Marinos C. Dalakas MD 